Fecha de recepción: abril 2021

Fecha de aprobación: mayo 2021

Fecha publicación: junio 2021

\section{Dibujar la Forma en el Espacio. Ejercicios de Desarrollo Secuencial para el adiestramiento creativo en el Diseño de Producto}

Cayetano José Cruz García ${ }^{(1)}$

\begin{abstract}
Resumen: Capacitar en la ideación de nuevos objetos requiere del desarrollo de la imaginación. Mediante una metodología sustentada en ejercicios de dibujo de "desarrollo secuencial", a modo de los iniciados por J. Albers, se produce un control de la imaginación creativa desde un proceso evolutivo, abierto a la toma de decisiones, y la relatividad de la Forma y el Espacio. Fundamentos básicos de la percepción háptica permiten explicar la condición propioceptiva del objeto de representación, de modo que la Forma y el Espacio son una consecuencia. Se produce un control del proceso de ideación que permite adiestrar y explicar cómo son las cosas y cómo nacen; ayudando a predecir el comportamiento y posibles necesidades en fases de un proceso de fabricación. Por tanto, se fomenta la inteligencia intuitiva en el ejercicio creativo, puesta a disposición del proceso de diseño.
\end{abstract}

Palabras clave: Dibujo - Diseño - Imaginación - Creatividad - Evolución - Cinestesia Materia - Tiempo - Forma - Espacio

[Resúmenes en inglés y portugués en la página 213]

(1) Cayetano José Cruz García es Doctor en Bellas Artes por la Universidad de Sevilla, y Profesor del área de Dibujo del Grado de Ingeniería en Diseño Industrial y Desarrollo de Producto del Centro Universitario de Mérida en la Universidad de Extremadura (UEx) (España), desde 1999. Es "Embajador de Diseño Latino" del Foro de Latinoamericano de Escuelas de diseño y participa como docente en carreras de postgrado DC de la Universidad de Palermo (Buenos Aires). Es miembro del Grupo de Investigación GEA (Evolución Artificial) de la UEx, donde ha participado en diversos Proyectos Nacionales de Investigación, un Proyecto Europeo, y ha coordinado diversos contratos de investigación con instituciones y empresas, dedicados al Arte, el diseño de producto y la Artesanía. Entre algunas de sus últimas publicaciones de 2019 y 2020, se destacan: "Esculpir la Forma. Una metodología secuencial de dibujo para la enseñanza del diseño de producto", "Hacia un ontológico de Creatividad aplicado al contexto del Diseño y Artesanía: Innovación y Computación Evolutiva", "Analyzing emotional lines in co-evolutionary art" y "Drawings in movement and gestualization”.ccruz@unex.es 


\section{Desarrollar la capacidad de imaginar}

El presente artículo es fruto del desarrollo experimental, de contenidos y ejercicios realizados durante varios años en la asignatura de Diseño y Creatividad, en el marco de la formación de diseñadores de industriales de producto. Concretar este contexto es fundamental, para entender que es importante desarrollar y hacer partícipe a la imaginación en el proceso creativo, tanto en el aspecto pedagógico como en la acción de idear un nuevo producto. Imaginar cómo nacen los objetos es saber cómo son y cómo podrían llegar a ser posibles (Cruz, C. J., 2013).

Existe una gran diferencia entre el potencial creativo y el rendimiento creativo real. En investigaciones, se determina que el "pensamiento divergente" expresa el "potencial creativo" y, en pruebas realizadas, se atestigua cómo no es posible garantizar el logro creativo real (Runco, M. A., \& Acar, S., 2012). La investigación de la creatividad tiene un amplio desarrollo hacia la búsqueda de métodos para apoyar ese potencial creativo, y desarrollar el rendimiento creativo. En este sentido, el diseño implementa metodologías (Jones, J. C., 1981), que permiten incorporar la inteligencia creativa desde el pensamiento divergente, en un orden supeditado al proyecto (Cross, N., 1999). Esto se visualiza en la diversidad de soluciones que se manifiestan, por ejemplo en un estado de brainstorming. Pero la toma de decisiones, ya sea frente a la divergencia o el progreso del desarrollo, debe estar sujeta a análisis y comprensión de la solución. Esto supone que el pensamiento de diseño debe entender y controlar el proceso que hace posible los logros.

¿Cómo obtener esta manifestación gráfica del pensamiento?, y en especial, ¿cómo posibilitar la capacidad de variar la solución durante el proceso de ideación?

En este sentido, ¿pueden los ejercicios de desarrollo secuencial permitir controlar el proceso, y hacerlo versátil y divergente desde la condición particular del individuo?

La experiencia creadora de algunos diseñadores y/o su habilidad particular, hacen que la solución de diseño sorprenda, y manifieste su capacidad innovadora. Se pone de manifiesto el creative leap, o "salto creativo" que surge como una inspiración inmediata (Dorst \& Cross, 2001, p. 425). Por este motivo, pudiera ser idóneo adiestrar el desarrollo creativo personal, que manifieste valores intuitivos y personales del individuo en el proceso de diseño.

Comprender es inventar, y permite a los educadores centrarse en la expresión del individuo (Runco, M. A., 2003). Esto permite afirmar que atender a la observación, como medio para analizar los objetos, ayuda a potenciar la imaginación creativa; ahora bien, esta observación debe ir más allá de la acción visual, para comprender cómo son las cosas. Así, debiera ser una observación integral, si se pretende asimilar las sensaciones que provocan a nuestros diversos medios sensoriales. Estos factores son atendidos desde el diseño en cuanto se aprecia la relación de affordance, las que mantienen los productos con los usuarios (Norman, D. A., 1999). El objeto manifiesta su propia personalidad, y quizá pudiera ser entendido desde su perspectiva.

Por tanto, ¿es posible dibujar un objeto desde su particular relación con el entorno?, ¿atender a la "propiocepción del objeto"? ¿Cómo es posible desarrollar o tener un control sobre lo imaginado? Si el pensamiento divergente se manifiesta durante el proceso de ideación, y pudiera ser modificado y variable durante el mismo, ¿cómo hacerlo visible atendiendo a la 
mencionada propiocepción del objeto? Hay una importante relación entre la imaginación y la creatividad (Lieberman, J. N., 2014), y la experimentación será importante para ayudarnos a entender el objeto. El "factor lúdico" es un medio para favorecer la experimentación desde la acción creativa (Ham, D. A., 2016), aplicando metodologías que propician la inventiva y aprovechen el "flujo creativo" (Mihaly, C., 1996).

\section{El dibujo como discurso}

Es habitual observar cómo muchos iniciados en el diseño tienen dificultades para expresar la forma y el espacio. En muchas ocasiones, las metodologías aplicadas para la enseñanza se suelen centrar en comprender sistemas de representación, y analizar la forma desde la observación. No es tan habitual que las enseñanzas se centren en adiestrar desde el descubrimiento sorpresivo, de la Forma y el Espacio. Sin embargo, hemos visto la importancia de generar inputs que permitan inspirar una solución.

¿Qué significa esto? Que la aproximación a la descripción se realiza desde un alumbramiento más o menos espontáneo (Figura 1). Esta aproximación responde al mencionado "salto creativo", pero, ¿cómo hacerlo útil?

El dibujante debe tener formación previa sobre cómo comunicar la Forma y su función, para hacer útil el salto creativo; y, si no es así, hay que realizar análisis sobre las estructuras y recursos que expresan esa morfología, dirigida a expresar la función de esa Forma. Indicar cuál es el diseño estructural que subyace en la Forma, y manifestar rasgos que identifique la morfología (Figura 2).

La representación de los dibujos espontáneos permite inspirar la imaginación, pero el desarrollo sucesivo precisa de un discurso. Una dialéctica del boceto provoca la transformación secuencial de las imágenes, y el diseñador determina la coherencia del desenlace final (Goldschmidt, G., 1991).

Entonces, ¿cómo lograr que una solución dibujada sea fruto de una historia o discurso, en el que los desenlaces avancen sucesivamente hacia una solución? El niño lo hace de manera natural cuando dibuja, y dialoga manifestando una historia (Figura 3). Tanto el garabateo como el dibujo discursivo son medios y recursos naturales, que utiliza el creativo y que se manifiestan en el dibujante o diseñador, desde su infancia a la madurez. Esta es la razón por la que no es positivo coartar el entusiasmo creativo durante la infancia, y necesario atenderlo en las sucesivas edades del individuo, sea la disciplina artística que sea y la diferente función de la manifestación artística. 


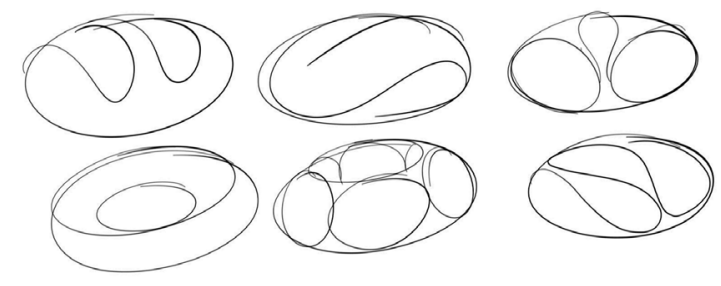

1

2
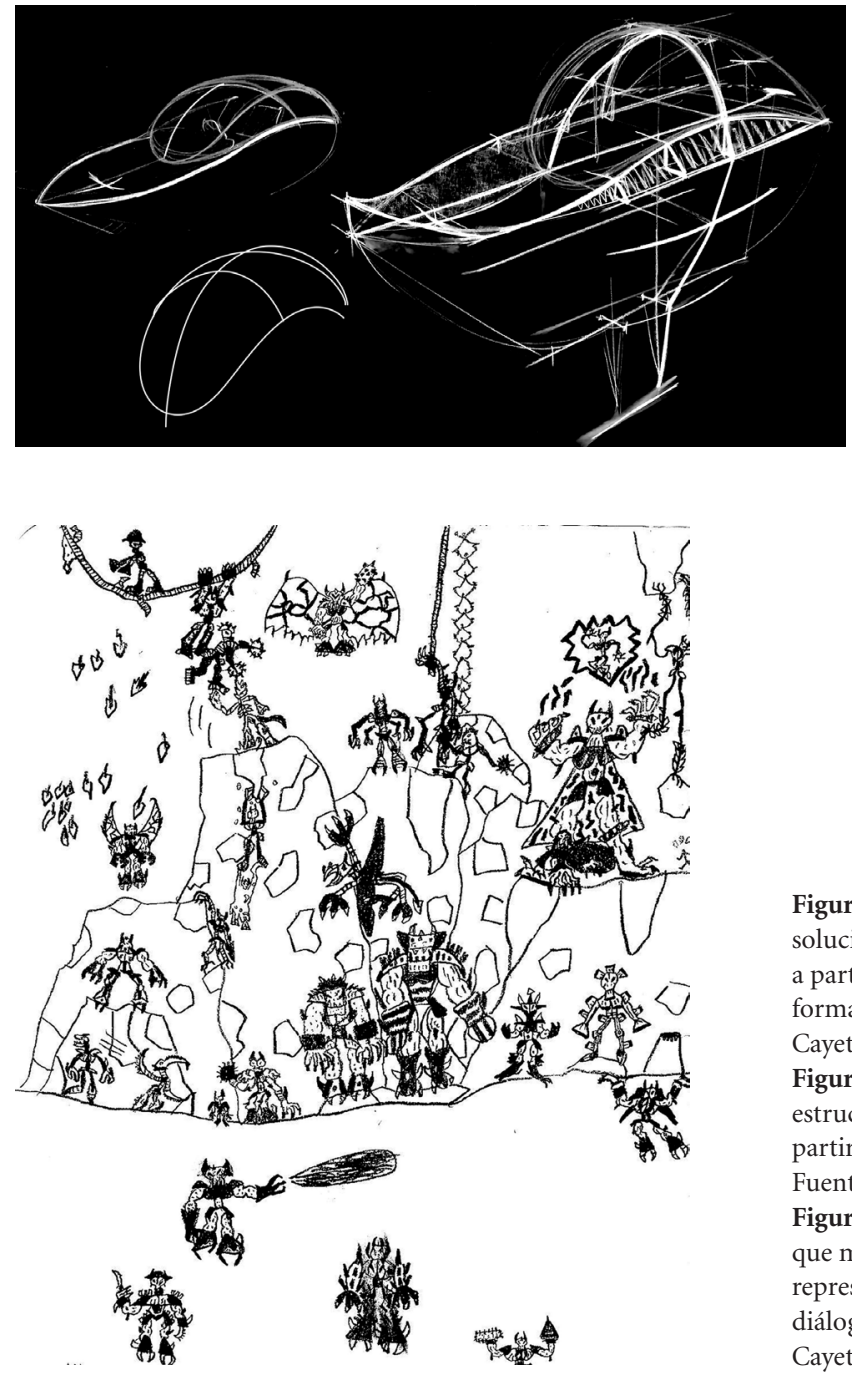

Figura 1. Diversas soluciones espontáneas a partir de una misma forma global. Fuente: Cayetano Cruz.

Figura 2. Sketch de estructura y morfología a partir de forma inspirada. Fuente: Cayetano Cruz.

Figura 3. Dibujo que manifiesta la representación del diálogo infantil. Fuente: Cayetano Cruz. 
Adolescentes o jóvenes afrontan el aprendizaje del diseño, y pueden venir con carencias o prejuicios sobre su capacidad para expresar las imágenes de su imaginación. Esta dificultad de aprendizaje debe abordarse en los centros de diseño, que luchan por dotar de medios expresivos al futuro diseñador, en un tiempo limitado. Algunos mejoran y otros continúan teniendo notables dificultades, hasta el punto de obtenerse soluciones notablemente infantiles. Sin embargo, las soluciones que dibujan en CAD suelen ser destacadas. Por tanto, ¿es tan necesario que los dibujos manifiesten una cualificación alta en el ejercicio a "mano alzada"? ¿Cuál pudiera ser la función de estos dibujos?, ¿cómo podemos agilizar el aprendizaje del dibujo, frente a las dificultades?, ¿cómo podemos ayudar a desarrollar la imaginación y su expresión dibujada? Estas y otras preguntas sugieren respuestas para el docente, que debe implementar metodologías para el aprendizaje.

\section{Un proceso natural y evolutivo de aprendizaje en el dibujo}

En el presente ensayo se pone de manifiesto un modo enseñanza, aplicado en sucesivos años de docencia; que ha permitido que futuros diseñadores den valor al discurso, $y$ adquieran destrezas para la comunicación de la forma y el espacio. Se pretende que el contenido de texto e imágenes permita comprender la función y sentido de estos aprendizajes. El ejercicio de trazar para dibujar responde a movimientos naturales de psicomotricidad gruesa. Es importante que antes estén claros y se recupere la naturalidad de movimiento, si es que se ha perdido. Este escenario es bastante común; ya que parte de malos modos adquiridos y provoca mitificaciones del dibujo, que generan inseguridad, ansiedad, entorpecimiento descriptivo, etc. Por ejemplo, es habitual encontrar a estudiantes zurdos que han distorsionado la posición de su cuerpo y los movimientos, en pro de visualizar la escritura y atender a la psicomotricidad fina. Esta circunstancia se da también en muchos diestros con prejuicios; mal aleccionados y acostumbrados a trazados de psicomotricidad fina; u obsesionados con borrar continuamente sin criterio, porque "está mal". Estas y otras premisas limitan la fluidez expresiva, y no favorecen el discurso gráfico.

El cuerpo debe moverse con naturalidad y favorecer el discurso, que debe soportar el pensamiento de diseño. Esta es una circunstancia por la que deben hacerse ejercicios que favorezcan la destreza, y que lo hagan sin dejar de lado el "flujo creativo" y la manifestación del "potencial creativo" del individuo.

La destreza del trazado, permite manifestar el impulso hábil para manifestar el pensamiento de un dibujante que pretende elaborar un discurso, con el fin de diseñar. Esta destreza se pone al servicio de ejercicios que puedan explicar la Forma de manera más intuitiva, y que así ayuden a motivar la expresión del "potencial creativo". De este modo nace un modo de dibujo más natural, que tiene en cuenta la evolución del pensamiento, y que es adecuado para los diseñadores de producto. Son los conocidos como "ejercicios de desarrollo secuencial", que J. Albers y otros diseñadores emplearon como disciplina para ayudar a expresar la Forma (Dantzic, C. M., 1999). 


\section{Los ejercicios de desarrollo secuencial}

\section{Características}

Los Ejercicios de Desarrollo Secuencial expresan el crecimiento de la Forma de manera progresiva. El aprendizaje a través de esta metodología, permite entender cómo nacen algunos de los objetos y formas que nos rodean. Por este motivo, no sólo es conveniente realizarlos para adiestrarnos en la manera de entender la forma y su dibujo, sino también para capacitarnos en la ideación de la misma. Hay una serie de condiciones que contemplar a la hora de abordar los dibujos, y que se van a mostrar siguiendo un guion, que permite ayudar en el aprendizaje del dibujo:

1. Los Ejercicios de Desarrollo Secuencial van a poder manifestar, de manera sencilla, la relación entre la Forma y el Espacio. Esto es así, porque utilizan la propiocepción del objeto frente al espacio. ¿Qué quiere decir esto? Que el objeto se va a expresar indicando la dirección del plano, y esta dirección o direcciones, manifiestan la posición del mismo. Por tanto, es fundamental tomar conciencia de que el plano determina la posición y otorga rasgos formales (Figura 4a), que van a ir creciendo según progresa el tiempo (Figura 4b). Si nuestro elemento de expresión formal es el Plano, es importante identificar cuáles son las direcciones principales que expresan la forma determinada (Figura 4c).

2. La construcción de la forma se realiza desde las partes al todo. Es decir, desconocemos cuál va ser la solución final. Lo importante es avanzar en la toma de decisiones, utilizando el potencial creativo. Esta norma responde a una de las leyes que está presente en la percepción háptica, Principle of Successive Perception (Révést, 1950: 94). Al igual que el ciego reconoce el todo a través de descifrar las partes, el diseñador puede indicar el progreso de la forma, sin verse limitado a cómo será la solución final. Además, la indicación de la forma está sujeta al análisis específico de las partes y la síntesis que expresan las direcciones del plano; por tanto, esta acción corresponde con el Principle of Structural Analysis (Révést, 1950: 109), y permite concretar el Principle of Constructive Synthesis (Révést. 1950: 118). Así, la sucesión de toma de decisiones va a determinar tanto la posición del objeto en el espacio (Figura 5), como la estructura y morfología del mismo (Figura 6).

Como ha podido apreciarse, la determinación de la construcción y posición del objeto se realiza progresivamente, según se avanza en el tiempo. Desde una síntesis, es posible hacer crecer la complejidad de la Forma. Esto supone un adiestramiento que se concreta desde la síntesis estructural. El progreso del diseño se pone de manifiesto mediante la suma de "micro-soluciones", en pro de una solución final. Cada "micro-solución" se aborda desde la capacidad de imaginar y comunicar la indicación deseada. Es decir, cada individuo expresa aquello que es capaz de expresar, de modo que es consciente de la sintonía entre lo imaginado y lo dibujado; de modo que el dibujo manifiesta el "cómo nace la Forma" y, por tanto, "cómo se hace la Forma". Esto supone tener consciencia de los posibles momentos del proceso de fabricación. 

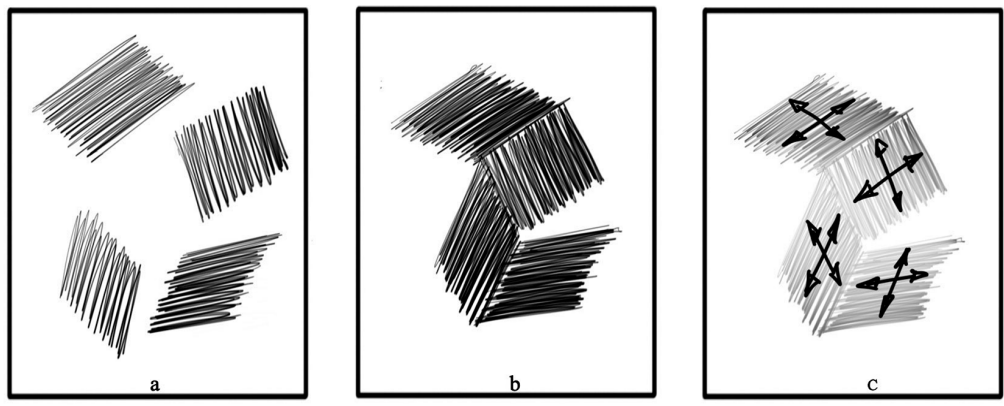

4
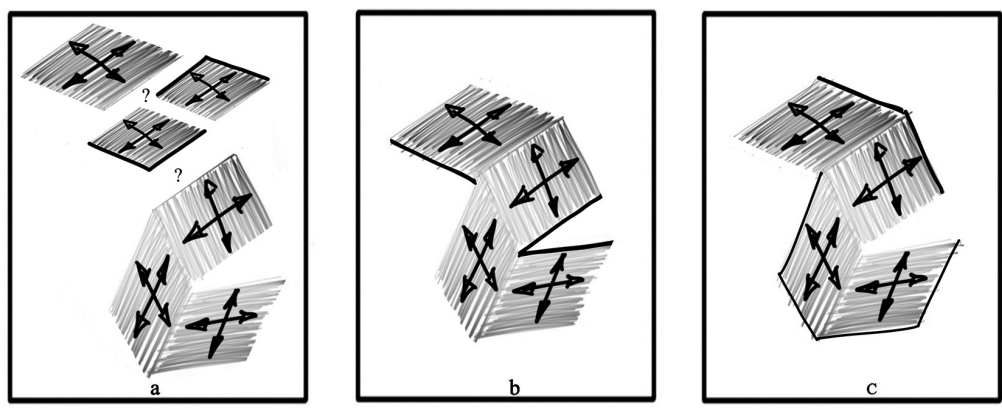

5
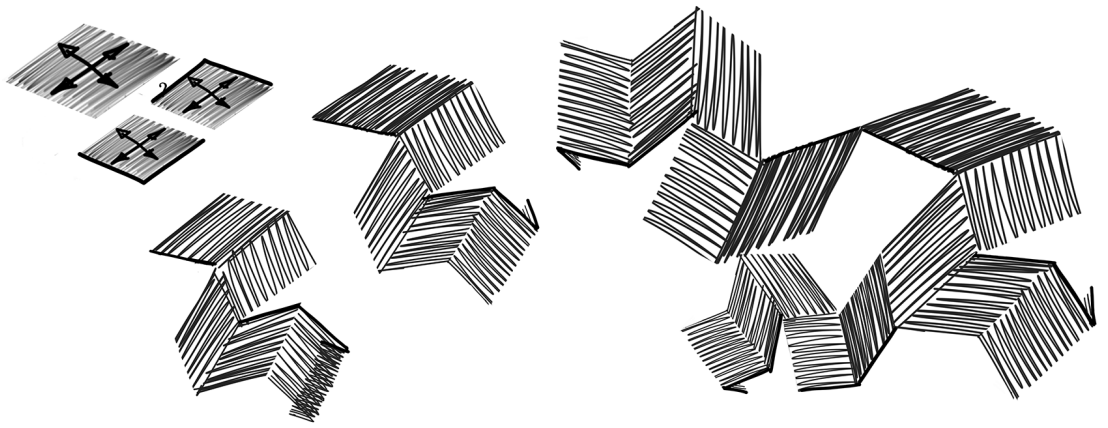

6

Figura 4. Las direcciones del plano determinan la Forma y posición del objeto, que está condicionada a futuras tomas de decisiones. Fuente: Cayetano Cruz García. Figura 5. Expresión de la variabilidad de la posición espacial del objeto, según necesidades. Fuente: Cayetano Cruz García. Figura 6. Expresión de la diversidad estructural según la toma de decisiones, mediante la construcción de la Forma desde las partes al todo. Fuente: Cayetano Cruz García. 
Para que se entienda el concepto y cumplir con un aprendizaje adecuado, es necesario realizan ejercicios con diverso nivel de dificultad. Ellos permitirán un desarrollo cognitivo que permita manifestar el potencial creativo. En el transcurso del artículo se manifiestan estos niveles, apoyados con dibujos que clarifican las condiciones.

\section{Ejercitación para el aprendizaje}

La secuenciación del proceso de ideación implica tomar consciencia del Tiempo (T), y el ritmo. Esto supone apreciar cómo el ritmo permite expresar las propiedades intrínsecas de la Materia (M). Así, el ritmo de la secuencia puede ser homogéneo o no, y más o menos dinámico. Por este motivo, en los ejercicios de iniciación es importante indicar que partimos de una línea temporal; que denominaremos "pauta temporal", y que va a condicionar el recorrido de la Forma (Figura 7a). Es importante considerar que la pauta temporal de $\mathrm{T}$ es sólo una referencia del recorrido, por tanto, es importante recalcar que no se está indicando el grosor visible del plano.

Durante el progreso del Tiempo la dirección del plano tiene un recorrido que hacer. La Forma (F) final y el Espacio (E) son una consecuencia. Para que pueda entenderse mejor, se indican a continuación la serie de niveles iniciales de aprendizaje; atendiendo a dos parámetros concretos de: dirección (d) del plano, y tamaño (t) de la dirección.

Nivel 1. Considera que " $t$ " es constante, y la dirección "d" es siempre la misma. Lo expresaremos de la siguiente manera, para que sirva de referencia en los siguientes niveles: $=\mathrm{t} /=\mathrm{d}$ (Figura $7 b$ ). Durante la ejercitación de este nivel el iniciado se familiariza con la dinámica; entendiendo que la dirección expresa el plano y la Forma surge y de manera secuencial ocupa un espacio. Como puede apreciarse (Figura $7 b$ ), las cuatro soluciones responden al deseo de expresar la forma de una cinta; independientemente de la posición que ocupa, lo importante es el objeto de representación; siendo todas las soluciones válidas. Por tanto, se pone de manifiesto el valor de "divergencia" de soluciones. Además, la posición de cada una de las soluciones podría girarse, y la descripción espacial funcionaría. Esto permite constatar la importancia propioceptiva del objeto, cuando la Forma nace secuencialmente de las partes al todo.

Nivel 2. Considera que " $t$ " es variable secuencialmente mediante la expresión de gradientes, y la dirección "d" es constante. Lo expresaremos de la siguiente manera, para que sirva de referencia en los siguientes niveles: $\pm \mathrm{t} / \mathrm{l}$ d (Figura 8). En el nivel 2 se pone de manifiesto una potenciación del factor espacial mediante el uso de gradientes; de mayor a menor tamaño, grosor e intensidad, o viceversa, es posible decir que una parte está más o menos cerca. Es muy importante que la variación del tamaño sea secuencial, porque si no si indicarían rasgos formales; como, por ejemplo, que una cinta sea más estrecha por unas partes frente a otras. 